\title{
AN OBSERVATIONAL STUDY ON USE OF MISOPROSTOL IN TERMINATION OF UNINTENDED PREGNANCY IN A RURAL SETTING
}

\author{
BANU N ${ }^{1}$, AKHTER QS ${ }^{2}$
}

\begin{abstract}
:
Background: Menstrual regulation (MR) is the abortion method in Bangladesh, majority of unwanted pregnancies are nevertheless induced by unskilled persons using different abortifacients. Now-a-days, in Bangladesh, the women of rural areas have found such an alternative in 'tablet misoprostol' which is introduced to them by the drug sellers, rural health service providers, and non-technical hospital staffs.
\end{abstract}

Objectives: The objective of this study was to investigate the experience, achievement and satisfaction of clients with acceptability and safety of misoprostol.

Methods: This observational study was carried out on all the patients attending outpatient as well as inpatient departments with a history of abortion at Chakaria Upazilla Health Complex, Cox's Bazar from October, 2009 to April, 2010. But the patients who had a history of misoprostol induced abortion only were treated as the sample.

Results: Out of the 66 abortion patients (study population), 43 were the sample (65.15\%). Women took vaginal bleeding as achievement for termination of pregnancy, no mater whether it was complete or partial. Side effects of the drugs e.g. pyrexia, shivering, vomiting and cramp were short lasting and were within tolerance level, and thus induced women to accept the procedure gladly. All of them accepted it for future use (100\%) and would recommend the procedure for friends and family (100\%).

Conclusion: The present study found an off-label use of misoprostol by the women themselves as abortifacients in a poor rural setting in Bangladesh. The women used the drug as they found it safe, cost effective and efficacious, and a self applicable home method. Its availability in open market (as an antiulcer drug) also facilitates its use.

Key Words: Misoprostol, termination of pregnancy, induced abortion, rural women.

J Dhaka Med Coll. 2010; 19(2) : 109- 114.

\section{Introduction:}

The issue of unsafe abortion remains one of the most neglected public health challenges in the developing countries. Millions of women around the world experience unintended pregnancies each year and many seek abortions $^{1}$. In every minute a woman in the developing world dies from complications of pregnancy and child birth ${ }^{2}$ and in every eight minutes another dies from complications of unsafe abortion ${ }^{3}$. According to the World Health Organization (WHO), maternal mortality from unsafe abortion ranges from $8 \%$ in Western Asia to $26 \%$ in South America, with a world wide average being $13 \%{ }^{4}$. It is to be noted here that one fifth of all pregnancies (42 millions out of 210 millions) each year are voluntarily aborted. Of these, 22 millions abortions occur within a formal health care system and 20 millions outside of legal system-. Nearly $48 \%$ of all induced abortions throughout the world are unsafe. In the developed countries, about $92 \%$ induced abortions are safe, whereas more than $55 \%$ are unsafe in the developing

1. Dr. Nasreen Banu, Junior Consultant, Obstetrics \& Gynaecology, Upazilla Health Complex, Chakaria, Cox's Bazar.

2. Dr. Qazi Shamima Akhter, Associate Professor, Department of Physiology, Dhaka Medical College, Dhaka. Correspondence: Dr. Nasreen Banu, Junior Consultant, Obstetrics \& Gynaecology, Upazilla Health Complex, Chakaria, Cox's Bazar. 
countries $^{1}$. Globally one in eight maternal deaths is due to unsafe abortion ${ }^{5}$. While $50 \%$ of all maternal deaths in Africa are due to unsafe abortion ${ }^{6}$, it is $8 \%$ in India ${ }^{4}$ and $14 \%$ in Bangladesh 7 . Medication abortion may be easier to incorporate into medical practice ${ }^{8}$. In fact, women are turning to the medical methods of abortion as it maintains privacy and is non- invasive ${ }^{9}$. Where the law prohibits abortion, the issue of methods and safety is immaterial. In that case, women need an alternative, which is relatively safer and easier to the existing unsafe procedures. Rural women of Bangladesh have found such an alternative 'tablet misoprostol' (prostaglandin $E_{1}$ analogue; an antiulcer drug) in breaking the existing methods of induced abortion. The drug was introduced to the women by the drug sellers, rural health service providers (medical assistants, family welfare assistants, nurses) and non-technical hospital staffs (aya, sweeper). In fact, they helped to popularize this new approach of pregnancy termination. Women accept it more gladly and rapidly because it is noninvasive, cost effective and a self applied home method and is obtained legally and easily from market. This yields an immense benefit for women. Aside from maintaining privacy, this procedure eliminates the effort to look for helping hands to perform the abortion and thereby, sparing them from embarrassment. They also found it safer than other conventional methods with regard to the complications. However, due to lack of standardized information and instructions, women utilized this drug in various ways with a high degree of variation in dose, dose schedule and route of administration. They used this tablet to bring back period and consider it effective when bleeding starts, no matter whether it is threatened, partial or complete abortion. Essentially, the drug induces less life threatening morbidity than any other methods. Yet, it causes sufficient bleeding to seek medical care as a kind of "passport" to get entry into the hospital, where her abortion is performed legally and safely. The objective of this study was to investigate the experiences of the clients who took misoprostol for abortion instead of existing unsafe methods and to measure the achievement and satisfaction of the clients with acceptability and safety of the drug (misoprostol) in inducing abortion.

\section{Methods:}

This observational study was performed at Chakaria Upazilla Health Complex, Cox's Bazar, from October 2009 to April 2010. All abortion related patients from inpatient and outpatient departments were the study population. Those who had misoprostol induced abortion were the samples. The samples were selected purposively. After taking an informed verbal consent from the patients, all information were collected through personal interviews, clinical examinations, from hospital records and relevant investigations (where applicable). The privacy and secrecy was maintained in each case. Finally data were compiled and analyzed manually. The diagnosis of abortion was done by taking the history of amenorrhea with early signs and symptoms of pregnancy, with or without positive urine test for pregnancy followed by bleeding. This history was clinically correlated with the uterine size (>normal), cervical consistency (soft rather than firm), with any amount of vaginal bleeding.

\section{Operational definitions:}

Achievement of the client: Establishment of the process of abortion (vaginal bleeding) after using tablet misoprostol was considered as the achievement/success of the client.

Safety of the drug: Measured by the amount of bleeding (huge- needs emergency hospitalization or blood transfusion; moderatelike heavy menstruation and light- as normal menstruation) and signs of infection (fever, foul smelling vaginal discharge and abdominal tender mass).

Acceptability of the drug: Measured by the side effects of the drug (fever, shivering, vomiting and abdominal cramp).

Satisfaction of the client: Reuse of the method and recommendation of the drug for others as 
abortion pill were measured as client's satisfaction.

Limitations of the study:

All misoprostol user women were not reported to the hospital. Only those patients who reported with partial or threatened abortion were the samples. Moreover, those who continued pregnancy or switched over to other invasive procedure or sought medical advice in other health care facilities after taking tablet misoprostol could not be included in this study. Besides, due to the legal restriction on abortion, it was actually impossible to deliver the information about the drug to the client or to prescribe it to those who seek abortion. As the clients took the drug by themselves, a standardized regime of drug dose, dose schedule and route of administration could not maintained. As such the efficacy and safety of the drug could not be compared with the other procedures of pregnancy termination.

\section{Results:}

Chakaria Upazilla under Cox's Bazar district is about $503.78 \mathrm{sq} . \mathrm{km}$. in area with an approximate population of 476581 . Among them 247822 are women. The literacy rate of the population is $54 \%$. There is one 50 bedded government hospital with 10 doctors including specialists for the entire population. In the observational study that covered 66 abortion patients samples were 43. Majority of the cases were married (74.41\%) middle aged (20-39 years) women; although teen aged (06.97\%) single girls (09.30\%) were not exempted. Majority of the women were from middle class $(65.11 \%)$ with educational status either nil $(n=21 ; 48.83 \%)$ or primary and below $(48.83 \%)$. Most of them choose first trimester to induce abortion (83.72\%). Misoprostol as abortion pill were prescribed to the clients mostly by the pharmacists $(37.20 \%)$ and rural health service providers $(41.86 \%)$, whereas, a few got from nontechnical hospital staffs (11.627\%). Parity was immaterial in relation to termination of pregnancy as shown in Table-I.
Table-I

Sociodemographic factors of misoprostol induced abortion cases

\begin{tabular}{|c|c|c|}
\hline Age & Number & Percentage \\
\hline 16- 19 years & 03 & $06.97 \%$ \\
\hline 20- 29 years & 23 & $53.48 \%$ \\
\hline 30 - 39 years & 21 & $48.83 \%$ \\
\hline 40 - 49 years & 05 & $11.62 \%$ \\
\hline \multicolumn{3}{|l|}{ Marital status } \\
\hline Married & 32 & $74.41 \%$ \\
\hline Single (never married) & 04 & $09.30 \%$ \\
\hline Single (married) & 07 & $16.27 \%$ \\
\hline \multicolumn{3}{|c|}{ Educational Qualification } \\
\hline Nil & 21 & $48.83 \%$ \\
\hline$<$ Primary & 21 & $48.83 \%$ \\
\hline$<$ Secondary & 06 & $13.95 \%$ \\
\hline d"Higher secondary & 02 & $04.65 \%$ \\
\hline \multicolumn{3}{|l|}{ Socioeconomic condition } \\
\hline Lower middle class & 17 & $39.53 \%$ \\
\hline Upper middle class & 10 & $23.25 \%$ \\
\hline Upper class & 05 & $11.62 \%$ \\
\hline \multicolumn{3}{|l|}{ Gestational age } \\
\hline$<12$ weeks & 36 & $83.72 \%$ \\
\hline$>12$ weeks & 07 & $16.27 \%$ \\
\hline \multicolumn{3}{|l|}{ Parity } \\
\hline 0 & 04 & $09.30 \%$ \\
\hline 1 & 12 & $27.90 \%$ \\
\hline 2 & 14 & $32.55 \%$ \\
\hline$>3$ & 13 & $30.23 \%$ \\
\hline
\end{tabular}

Misoprostol prescribed by the persons

Pharmacist $16 \quad 3720 \%$

Rural health service provider* $\quad 18$

$41.86 \%$

Non-technical hospital staff ${ }^{\star *} \quad 05$

$11.62 \%$

Friends and family $\quad 04 \quad 09.30 \%$

(medical assistant, family welfare assistant)*, (aya, cleaner)**

All of them would accept it for future use and would recommend the procedure for friends and family as shown in Table-II. 
Table-II

Client's achievement, acceptability, satisfaction and safety of using misoprostol

\begin{tabular}{lcc}
\hline & Incidence & Percentage \\
\hline $\begin{array}{l}\text { Misoprostol induced } \\
\text { Vaginal bleeding }\end{array}$ & $43 / 43$ & $100 \%$ \\
Misoprostol induced & & \\
$\quad$ Vomiting & $03 / 43$ & $06.97 \%$ \\
$\quad$ Shivering & $06 / 43$ & $13.95 \%$ \\
$\quad$ Cramping & $43 / 43$ & $100.00 \%$ \\
$\quad$ Pyrexia (short lasting)03/43 & $06.97 \%$ \\
Safety of Misoprostol in induced abortion \\
$\quad$ High Fever & $00 / 43$ & $0 \%$ \\
$\quad \begin{array}{l}\text { Foul smelling } \\
\text { vaginal discharge }\end{array}$ & $00 / 43$ & $0 \%$ \\
$\quad \begin{array}{l}\text { Abdominal tender } \\
\text { mass }\end{array}$ & $00 / 43$ & $0 \%$ \\
\multicolumn{2}{l}{$\begin{array}{l}\text { Satisfaction of clients in } \\
\text { Misoprostol induced } \\
\text { abortion }\end{array}$} & \\
$\quad \begin{array}{l}\text { Re use in future } \\
\text { Recommendation } \\
\text { to others }\end{array}$ & $43 / 43$ & $100 \%$ \\
\hline
\end{tabular}

\section{Discussion:}

Improvement of maternal health has been an issue on the global agenda for the last 20 years. It is found that socio-cultural, demographic and legal factors highly influence the maternal mortality and morbidity due to unsafe abortion ${ }^{10}$. Induced abortion has decreased from 46 million in 1995 to 42 million in 2003. By 2003, there were 26 abortions / 1000 women in developed countries whereas it was 29 / 1000 in developing countries. As such safe induced abortion is essential especially in parts of Asia, Latin America and Africa ${ }^{11}$. Growing body of evidence has now shown that misoprostol can be used as a single agent to induce early abortion $^{12}$. It is widely used in Brazil as an abortifacient ${ }^{13}$. Women are increasingly using misoprostol to safely terminate their pregnancy at home. Several studies have shown that the rate and severity of complications are significantly less among women who used misoprostol as compared with women who used invasive methods ${ }^{14}$. Data obtained from gynecologists confirmed that the drug influenced the reduction of complications of illegal abortions. It was also found that this type of induced abortion was more acceptable than other methods ${ }^{15}$. Similar results were also observed by the investigators of this study. Women are learning that they do not need to go for dangerous and unreliable abortion services availed by them previously. Many women, particularly in countries with restrictive abortion laws, attempt to terminate early pregnancies with misoprostol alone ${ }^{16}$. It is inexpensive, stable at ambient temperature, easy to transport, easy to administer and does not require refrigeration even in hot climate $^{17,18}$. One study reported that women chose home use misoprostol, because it was felt more natural, private and it allowed the presence of partner. Moreover, it would reduce the number of visits to hospital and improve access to medical abortion ${ }^{19}$. Thus, it has potential to significantly expand medication abortion access in developing countries. In USA, misoprostol has only been registered by the FDA for treatment and prevention of NSAID induced gastric ulcer. The FDA further approved the use of misoprostol in conjunction with RU-486 for termination of pregnancy ${ }^{16}$. Misoprostol only regime is not widely used in USA, where RU486 and misoprostol, methotraxate and misoprostol and aspiration abortion services are available. However, the off label uses of misoprostol as a single agent abortion pill has been documented among Latinas in USA ${ }^{18}$. In Britain and France, it has not been approved as abortion pill with or without RU-486. The drug's label has a contraindication for women of childbearing potentials. It is used in France for inducing abortion as off label. In Europe, women use misoprostol for two days to bring about a complete abortion. In Scotland, physicians have utilized the regimen as cost effective rather than utilizing hospital operation room ${ }^{13}$. Brazilian women began to use misoprostol since 1988 for induction of abortion, despite the fact that the drug is not registered as abortion pill (the package insert specifically states that the drug should not be used by the pregnant women because of its side effect of complete or incomplete abortion). The hospital admission due to misoprostol induced abortion increased from $12 \%$ in 1988 to $56 \%$ 
in 1989 and to $73 \%$ in 1990, indicating clearly that Brazilian women were experiencing new abortion technique during the period. A total of $70 \%$ of all evacuated cases in a Brazilian city hospital resulted from the use of misoprostol. This study found $65.15 \%$ abortion cases were misoprostol induced ${ }^{20}$.

The efficacy of misoprostol as abortifacient varies by route of administration, dose, dose schedule and gestational age. The misoprostol only regime has the potential to access to safe abortion services in resource poor setting and developing countries. Although it is not as effective as other existing safe medical abortion techniques, its side effects are much less than the combined medical methods of abortion $^{18}$. The present study has shown that off-label use of misoprostol by the women themselves as abortifacients exists in a poor rural setting of Bangladesh. Age, parity, gestational age, educational qualification and socio-economic conditions are immaterial, when the pregnancy is unintended. The women used the drug as they found it safe, cost effective and efficacious. It maintains privacy and is a self applicable home method. Its availability in open market (as an antiulcer drug) also facilitates its use.

\section{Conclusion:}

The evidence is clear that death and disability from induced abortion are greatly reduced by medical abortion. It provides a safe alternative to other dangerous interventional abortion methods. Medical abortion has the potential to widely reduce the number of unsafe abortion. In Bangladesh, misoprostol as the peptic ulcer drug is easily and legally available than unregistered RU-486 which is expensive and only available in private sector. Information about misoprostol as an abortion pill is spreading via family-friends, drug sellers and basic health workers rather than registered persons (doctors). Nowadays they recommend misoprostol more frequently than other techniques of induced abortion.

\section{Recommendation:}

This study would draw the attention of policy makers in health sector of Bangladesh to undertake a multi-centred trial in government registered Menstruation Regulation Clinic to compare the efficacy, safety, acceptability and cost effectiveness of misoprostol with existing MR procedure.

\section{References:}

1. Sedgh G, Henshaw S, Sing S, Ahmed E, Shah IH. Induced abortion: estimated rates and trends worldwide. Lancet. 2007; 370(9595): 1338-45.

2. Maternal Mortality in 2005: Estimates developed by WHO, UNICEF, UNFPA and the World Bank. World Health Organization (WHO). Geneva, Switzerland. 2007.

3. World Health Organization (WHO), Department of Reproductive Health. Unsafe abortion: global and regional estimates of incidence of unsafe abortion and associated mortality in 2003. $5^{\text {th }}$ ed. Geneva, Switzerland. 2007.

4. Kumar M. Unsafe abortion: a silent scourge. The Times of India. May 18, 2008.

5. Nour NM. An introduction to maternal mortality. Rev Obstet Gynecol. 2008; 1(2): 77-81.

6. Hord C, Wolf M. Breaking the cycle of unsafe abortion in Africa. Afr J Reprod Health. 2004; 8(1): 29-36.

7. Bangladesh Statistical Beauro. 2008. Ministry of Planning, Government of the People's Republic of Bangladesh.

8. Leeman L, Asaria S, Espey E, Ogbun J, Gopman $\mathrm{S}$, Barnett S. Can mifepristone medication abortion be successfully integrated into medical practices that do not offer surgical abortion? Contraception. 2007; 76(2): 96-100.

9. Medical Abortion: facts and information for healthcare professionals. Available from: http:// www.medicalabortion.com/references / index.html [Accessed on 21.06.2010].

10. Rossenfield A, Min CJ, Freedman LP. Making motherhood safe in developing countries. N Engl J Med. 2007; 356: 1395-7.

11. Antommttei O, Khanfer NM, Mujtaba BG. Global abortion and marketing challenges for misoprostol: the future of women's health. Int Business Econ Res J. 2009; 8(1): 105-12.

12. Blanchard K, Winikoff B, Ellertson C. Misoprostol used alone for the termination of early pregnancy: a review of the evidence. Contraception. 1999; 59: 209-17.

13. Coelho HL, Teixeira AC, Santos AP, Forte EB, la Vecchia C, Tognoni G, et al. Misoprostol and illegal abortion in Fortaleza, Brazil. Lancet. 1993; 341(8855): 1261-63. 
14. Costa SH. Commertial availability of misoprostol and induced abortion in Brazil. Int $\mathrm{J}$ Obstet Gynecol. 1998; 63(1): 131-9.

15. Barbosa R, Arilha M. The Brazilian experience with cytotec. Stud Fam Plann. 1993; 24(4): 23640 .

16. Singh G, Radhakrishnan G, Guleria K. Comperison of sublingual misoprostol, intravenous oxytocin and intravenous methylergometrine in active management of third stage of labour. Int $\mathrm{J}$ Obstet Gynecol. 2009; 107(2): 130-4.

17. Medical abortion: misoprostol alone. Available from http://www.medicationabortion.com/ misoprostol/index.html [Accessed on 20.06.2010]
18. Fiala C, Winikoff B, Helstrom L, Hellborg M, Gemzell-Danielsson K. Acceptability of Home-use of Misoprostol in medical abortion. Contraception.2004; 70(5): 387-92.

19. Rosing M, Archbald C. The knowledge, acceptability and use of misoprostol for selfinduced medical abortion in an urban US population. JAMWA. 2000; 35(3): 153-85.

20. Kelly M. Cytotec in Brazil: a legal alternative to illegal abortions. School of Public Health, Epidemiology Department. Available from: http:/ / cgi.unc.edu/research / pdf/cytotec.pdf. [Accessed on 21.06.2010] 